\title{
From time dependent intermittent selfcatheterisation to volume dependent selfcatheterisation in Multiple Sclerosis using the PCI 5000 Bladdermanager ${ }^{\circledR}$
}

\author{
D De Ridder ${ }^{1}$, H Van Poppel ${ }^{1}$, L Baert ${ }^{1}$ and $\mathbf{J}$ Binard ${ }^{2}$ \\ ${ }^{1}$ Katholieke Universiteit Leuven, Belgium and the National Centre for Multiple Sclerosis, Melsbroek, Belgium; \\ ${ }^{2}$ University of Southern Florida, Tampa, USA
}

\begin{abstract}
The use of portable, patient controlled, ultrasound device for the measurement of the bladder volume (PCI 5000, Bladdermanager ${ }^{\circledR}$ ) in the management of neurogenic bladder dysfunction in Multiple Sclerosis is presented. Twenty-three patients were transferred from time dependent intermittent catheterisation to volume dependent intermittent catheterisation using this device. Evaluation of the accuracy of the measurements showed an accuracy of $91.05 \%$. The efficacy per catheterisation improved significantly from $260.8 \mathrm{cc} \pm 154 \mathrm{cc}$ to $297.5 \mathrm{cc} \pm 138 \mathrm{cc}$. The frequency of incontinence measured during $48 \mathrm{~h}$ decreased on the entire group from 69 to 39 . Six patients could delete one catheterisation a day. Functional Independence Measurements (FIM score) did not show an increase of the level of assistance needed, using this device.
\end{abstract}

Keywords: Multiple sclerosis; intermittent selfcatheterisation; neuropathic bladder; ultrasound

\section{Introduction}

Multiple Sclerosis is a disease of the white matter of the brain and the spinal cord which causes impairment of nerve conduction. Urological problems are very common in the course of the disease. Almost $80 \%$ of the patients will present urinary symptoms. Frequency and urgency are the most common complaints. Urodynamic investigation shows detrusorhyperreflexia in half of the patients. Half of these will also present detrusor-sphincterdyssynergia. ${ }^{1,2}$ Treatment of this hyperreflexia consists mostly of using anticholinergics, eventually combined with tricyclic antidepressants. A variable degree of post voiding residual urine can be present. This residual urine is in many cases the first reason to initiate urological treatment to improve bladder emptying. Residual urine and chronic overdistension may play a role in the aetiology of progressive bladder dysfunction. Early prevention of residual urine is believed to be important in delaying the onset of incontinence. ${ }^{3}$ The treatment of the emptying disorder can be medical using alpha blocking agents, but often intermittent catheterisation is the best therapeutic option. ${ }^{2}$ However, the elimination of the residual urine does not always eliminate or improve symptomatic bladder hyperreflexia. Administration of anticholinergics is often necessary to control the hyperreflexia. Even then persisting hyperreflexia can lead to incontinence between catheterisations.

Correspondence: Prof. dr. L. Baert
Even so persisting subjective urgency can lead to an increased frequency of catheterisations, so often at low volume, in an attempt to avoid incontinence. Even in the absence of these problems, intermittent catheterisation is often performed too early or too late, leading to unnecessary catheterisations or to bladder overdistension. ${ }^{4}$ For this reason we designed a study using the Bladdermanager PCI $5000^{\circledR}$ to give the patient feedback on his bladder volume and to change his catheterisation schedule from time dependent to volume dependent. The accuracy of the measurements and the potential use as a patient controlled feedback training device are assessed.

\section{Materials and methods}

The PCI 5000 Bladdermanager $^{\circledR}$ is a portable, wearable, battery-powered ultrasound instrument designed to non-invasively monitor bladder volume on an intermittent basis. The system consists of a small sensor to measure the bladder volume and a batterypowered control unit where the measurements are calculated and displayed. At any time the unit can be activated by the physician or the patient and the device automatically performs B-modescans along 12 separate planes, each 15 degrees apart. These data are used to calculate the bladder volume. The display also shows icons indicating the battery status and the quality of coupling to the patient's skin. The device can also be worn continuously using a special garment and can be set to an automatic mode reporting on the bladder 
volume at pre-set time intervals. Twenty-five patients, 18 males and seven females with proven Multiple Sclerosis were included in the study. All of them were on a clean intermittent catheterisation program. Neurologically all patients were at least partially wheelchair bound, but had acceptable control of their upper limbs allowing them to catheterise without help. Two patients suffered from some cognitive and sensory impairment and were not always aware of their incontinence. All patients except one had involuntary losses of urine in between the catheterisation despite adequate medical therapy with oxybutinin and imipramin. A full urodynamic investigation was carried out within 3 months preceding the start of the study. Urinary tract infection was ruled out or treated if present. Before the study a micturition and catheterisation chart was kept during $48 \mathrm{~h}$, showing micturition and catheterisation time and volume and also the periods of incontinence. An ideal catheterisation volume was calculated as the mean of the cystometric bladder capacity and the functional bladder capacity derived from the urodynamic investigation and micturition charts. If not satisfactory this volume was adjusted during the first 5 days. Catheterisation time and volume were noted, as were the incontinence periods. During a period of 2 weeks patients were allowed to use the Bladdermanager ${ }^{\circledR}$. Initial instructions concerning the use of the device and the correct way of collecting data, were given during a training session of 1 to $2 \mathrm{~h}$, including at least one catheterisation and volume measurement. Measurements were performed every hour during the day and every $2 \mathrm{~h}$ during the night. This was done until the preset volume was reached. Measurements and catheterisations were done in supine position, although this is not necessary to obtain reliable results.

After 2 weeks a micturition chart was kept again during 2 days and was compared with the previous one. The ultrasound volumes and catheterised volume measurements were recorded and entered in the computer. The correlation between the pre-set volume and the catheterised volume was calculated using the Pearson correlation coefficient. The difference between catheterised volume and ultrasound volume was expressed as a mean percentage error of the catheterised volume. ${ }^{5}$ The Wilcoxon signed rank test was applied to the volume data. Contingency tables and the Chi-square test were used to evaluate the frequency of incontinence.

From the adult Functional Independence Measure (FIM) ${ }^{6}$ the scale for bladder control was used to assess the influence of this training on the independence of the patient. The bladder management scale consist of two separate scores, one for the frequency of incontinence and one for the level of assistance needed. The maximum score on each topic is 7 , meaning complete independence, the lowest score being 1, meaning total assistance. Only the lowest score of both is recorded as final score for the bladder management.

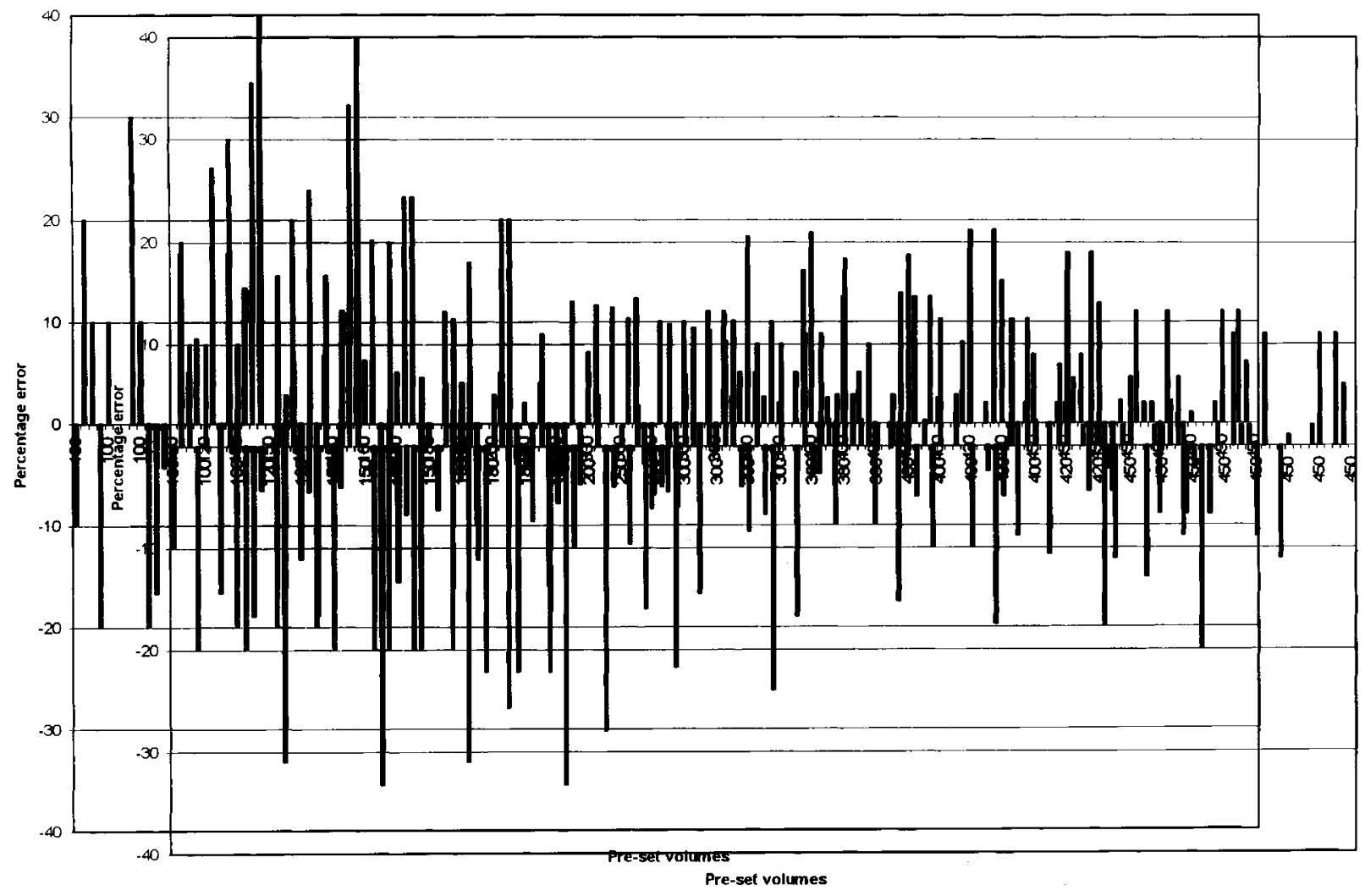

Figure 1 Percentage error per individual measurement at different pre-set volumes 


\section{Results}

Accuracy study

During the study period 215 measurements were performed with the PCI 5000 Bladdermanager ${ }^{\circledR}$, reaching the pre-set volume. At that time catheterisation was done and the catheterised volume was compared to the pre-set volume. The pre-set volumes ranged from 100 to $450 \mathrm{cc}$ with a mean of $298.2 \mathrm{cc}$ (median $=300 \mathrm{cc})$. The catheterised volumes ranged from 50 to $480 \mathrm{cc}$ with a mean of $297.5 \mathrm{cc}$ (median $=316 \mathrm{cc})$. The correlation between the two data sets was $95.6 \%$. The mean error was $-3.6 \mathrm{cc} \pm 36.2 \mathrm{cc}$. The error expressed as a percentage of the catheterised volume was $8.95 \%$, the maximum error being $40 \%$. Both overestimation and underestimation of the catheterised volume were encountered. The percentage error per pre-set volume is shown in Figure 1.

\section{Feedback training}

Three objective variables were measured to obtain an insight into the possible benefit of patient and volume controlled catheterisation: number of catheterisations, catheterised volume and periods of incontinence.

The mean catheterised volume for the whole group before the introduction of the PCI 5000 was $260.8 \mathrm{cc} \pm 154.5 \mathrm{cc} \quad($ median $=245 \mathrm{cc})$. After the instruction period and run in period of 14 days these numbers were $297.5 \mathrm{cc} \pm 138.9 \mathrm{cc} \quad($ median $=316 \mathrm{cc}$ ). Applying the Wilcoxon signed rank test as the statistical tool, this difference proved to be significant
$(P<0.001)$. The number of catheterisations could be diminished by one daily in six patients. The number of incontinent periods measured during $48 \mathrm{~h}$ for the whole group was decreased from 69 to $39(P<0.05)$.

To measure the objective effect of the device upon the level of assistance required the Functional Independence Measure (FIM scale) was used. For the purpose of this study both individual scores for bladder management are given in Table 1. The level of assistance remained the same in 15 patients, in five patients the level increased by one, in three patients the level decreased by one. Concerning the frequency of incontinence, a higher score (meaning less incontinence) is noted in 15 patients. The remaining eight patients had an unchanged score. When only the lowest and final score is taken into account the independence for bladder control increased in 13 patients and remained the same in nine patients. Only one patient decreased his total score and dropped out of the study due to severe cognitive deterioration due to a relapse of his neurological condition.

\section{Discussion}

Regarding the accuracy there is little doubt that the PCI 5000 Bladdermanager ${ }^{\circledR}$ is accurate enough to be used in a clinical setting. The correlation between catheterised and measured volume as well as the accuracy are excellent for an ultrasound measurement. Probably the target control incorporated in the control unit helps to eliminate partial or unreliable measurements. Other ultrasound devices - none of them being patient controlled - have been used for this

Table 1 Functional independence measure score

\begin{tabular}{|c|c|c|c|c|c|c|}
\hline Patient & $\begin{array}{l}\text { Pre-PCI level of } \\
\text { assistance }\end{array}$ & $\begin{array}{c}\text { Freq. of } \\
\text { incontinence }\end{array}$ & $\begin{array}{l}\text { Lowest } \\
\text { score }\end{array}$ & $\begin{array}{c}\text { Post-PCI level of } \\
\text { assistance }\end{array}$ & $\begin{array}{c}\text { Freq. of } \\
\text { incontinence }\end{array}$ & $\begin{array}{c}\text { Lowest } \\
\text { score }\end{array}$ \\
\hline PU & 6 & 3 & 3 & 6 & 7 & 6 \\
\hline TA & 6 & 3 & 3 & 6 & 7 & 6 \\
\hline SW & 5 & 4 & 4 & 4 & 7 & 4 \\
\hline LST & 5 & 2 & 2 & 5 & 4 & 4 \\
\hline $\mathrm{BG}$ & 4 & 1 & 1 & 4 & 2 & 2 \\
\hline $\mathrm{EF}$ & 5 & 2 & 2 & 5 & 2 & 2 \\
\hline SDR & 2 & 1 & 1 & 2 & 1 & 1 \\
\hline GK & 5 & 7 & 5 & 6 & 7 & 6 \\
\hline $\mathrm{ML}$ & 1 & 1 & 1 & 1 & 1 & 1 \\
\hline $\mathrm{KG}$ & 6 & 1 & 1 & 6 & 2 & 2 \\
\hline BS & 6 & 1 & 1 & 6 & 2 & 2 \\
\hline $\mathrm{NN}$ & 6 & 3 & 3 & 6 & 4 & 4 \\
\hline $\mathrm{FG}$ & 5 & 3 & 3 & 5 & 4 & 4 \\
\hline $\mathrm{TE}$ & 3 & 2 & 2 & 4 & 3 & 3 \\
\hline $\mathrm{RE}$ & 5 & 1 & 1 & 6 & 2 & 2 \\
\hline WH & 2 & 1 & 1 & 3 & 3 & 3 \\
\hline QA & 2 & 1 & 1 & 2 & 1 & 1 \\
\hline $\mathrm{HG}$ & 6 & 6 & 6 & 5 & 7 & 5 \\
\hline $\mathrm{ES}$ & 4 & 4 & 4 & 5 & 4 & 4 \\
\hline TT & 4 & 2 & 2 & 4 & 3 & 3 \\
\hline VG & 6 & 3 & 3 & 6 & 3 & 3 \\
\hline FA & 4 & 3 & 3 & 3 & 4 & 3 \\
\hline
\end{tabular}


purpose with correlations varying from $79 \%$ to $91 \%$. Also the calculation of the bladder volume is based on measurements in 12 different planes, being more accurate than the classic estimations in three planes. On the other hand the measurement of the catheterised volume and the ultrasound measurement were not performed by independent investigators, but by the patient, implicating maybe less accurate data collection. However, the differences between catheterised volume and measured volume hardly have any importance in a clinical setting. The most important feature however seems to be that this ultrasound unit can be used in a reliable way by patients or nurses without any ultrasound experience, after an initial training of less than $2 \mathrm{~h}$.

The data concerning the use of the PCI 5000 Bladdermanager ${ }^{\circledR}$ as a feedback training device are even more interesting. Intermittent catheterisation has been advocated by many authors as a treatment of choice for neurogenic bladder dysfunction in MS.,3 Kornhuber et al. performed an interesting study in 197 MS patients using initial intermittent catheterisation and ultra-sound controlled bladder training. By combining catheterisation with bladder training techniques these authors managed to reduce the residual urine considerably and to re-install a more normal voiding pattern, regardless of the initial urodynamic findings. This study proved that it is possible in MS patients to regain some of the lost bladder control by training, providing there is some kind of feedback on the bladder volume. Our patients selection however included patients with more advanced disease who all practised intermittent catheterisation over several months, but who had persisting hyperreflexia despite adequate medical treatment. Some patients suffered from involuntary losses of urine between catheterisations due to overflow, caused by deferred catheterisation. Using the PCI 5000 Bladdermanager ${ }^{\circledR}$ we were able to improve the urological status even in these patients, proving that even in advanced stages biofeedback training techniques can be useful.

This is very important from the rehabilitation point of view, since it improves the self-esteem of the patient, decreases his incontinence and consequent social problems, without increasing the level of assistance needed, thus increasing the quality of life.

The efficacy of the intermittent catheterisation was improved, since the catheterised volume increased in a significant way from $260.8 \mathrm{cc}$ to $297.5 \mathrm{cc}$, with the standard deviation decreasing. This enabled six patients to delete one catheterisation a day. The incontinence periods decreased from 69 to 39, which is highly significant. This obviously impacts on the patient's social life and on the expenses required for incontinence material. Long term studies on larger groups of patients are necessary to confirm this possible benefit.

The use of the Functional Independent Measure did allow us to draw different conclusions. The level of assistance remained the same in 15 patients, in five patients the level increased by one, in three patients the level decreased by one. This means that except maybe during the training phase, most patients do not require a higher level of assistance, despite the use of a new external device. These data show that it is possible to improve the functional urological status of a patient by decreasing his incontinence and improving his independence without increasing the assistance to be procured by the nursing staff. Thus the device could also help to achieve a lower general FIM score in a shorter period of time if urinary problems are to be treated by intermittent catheterisation. This would have to be confirmed in a larger study. We conclude that PCI 5000 Bladdermanager ${ }^{\circledR}$ can offer several benefits to patients with neurogenic bladder dysfunction, not only in Multiple Sclerosis but also in other aetiologies of spinal cord disorders. Currently the device costs approximately 6000 US\$. Further studies are needed to evaluate the possible economic benefit considering incontinence appliances, number of catheters needed, number of infections etc. Also the impact on the quality of life of these patients has to be considered in larger groups.

\section{Acknowledgements}

Thanks to Rev Sister Mia Costermans for her skilled assistance during the training of the patients.

\section{References}

1 Van Poppel H, Vereecken RL, Leruitte A. Neuromuscular dysfunction of the lower urinary tract in multiple sclerosis. Paraplegia 1983; 21: $374-379$.

2 Fowler CJ, Van Kerrebroek Ph, Nordenbo A, Van Poppel H. Treatment of lower urinary tract dysfunction in patients with multiple sclerosis. J Neurol Neurosurg Psych 1992; 55: 986-989.

3 Kornhuber HH, Schutz A. Efficient treatment of neurogenic bladder disorders in multiple sclerosis with initial intermittent catheterisation and ultra-sound controlled training. Eur Neurol 1990; 30: $260-267$.

4 Binard JE, Persky L, Lockhart JL, Kelley B. Intermittent catheterisation the right way! (Volume vs Time-directed). $J$ Spinal Cord Med 1996; 19: 194-196.

5 Coombes GM, Millard RJ. The accuracy of portable ultrasound scanning in the measurement residual urine volume. J Urol 1994; 152: $2083-2085$.

6 Guide for the Uniform Data Set for Medical Rehabilitation (Adult FIM), Version 4.0., Buffalo, NY 14214: State University of New York at Buffalo; 1993

7 Massagli TL, Cardenas DD, Kelly EW. Experience with portable ultrasound equipment and measurement of urine volumes: interuser reliability and factors of patient position. J Urol 1989; 142: 969. 